CORRECTION

\title{
Correction: Imbalanced post- and extrasynaptic SHANK2A functions during development affect social behavior in SHANK2-mediated neuropsychiatric disorders
}

Ahmed Eltokhi (D), Miguel A. Gonzalez-Lozano (D), Lars-Lennart Oettl (D), Andrey Rozov (D), Claudia Pitzer, Ralph Röth, Simone Berkel (D), Markus Hüser, Aliona Harten, Wolfgang Kelsch (D), August B. Smit (D), Gudrun A. Rappold (iD) and Rolf Sprengel (iD)

(c) The Author(s), under exclusive licence to Springer Nature Limited 2021

Molecular Psychiatry (2021) 26:6505; https://doi.org/10.1038/s41380-021-01218-7

Correction to: Mol Psychiatry https://doi.org/10.1038/s41380-02101140-y

The original version of this article unfortunately contained a mistake. Joint senior authors information was missing. The corrected information is given below.

Joint senior authors of the article https://doi.org/10.1038/s41380021-01140-y are: Gudrun A. Rappold and Rolf Sprengel.
Funding should read: Open Access funding enabled and organized by Projekt DEAL. AE was supported by the Heidelberg Biosciences International Graduate School (HBIGS). RS received support from the Ingeborg Ständer Foundation and AR from the RSBF (17-04-01528 A). RR, CP, SB, and GR are supported by the Medical Faculty of the Heidelberg University. WK was supported by a BMBF Grant (n. 01GQ1708).

The original article has been corrected. 